\title{
Capturing the Cosmos: Teaching Astronomy (and more) through Astrophotography in Middle School
}

Saeed Salimpour ${ }^{1 *}$

\begin{abstract}
The Universe provides a canvas for exploration, it sets the stage waiting to be captured and explored by imagination and science. Its capacity to provide innate aesthetically pleasing visuals and the mysteries they hold, piques the curiosity of everyone. This paper provides an overview and results from an astronomy elective as implemented in a middle school classroom over the course of 11 weeks, at a non-governmental school in regional Victoria, Australia. Students who previously had no exposure to astronomy or image processing used the Las Cumbres Observatory (LCO) network of robotic remote telescopes to capture images of astronomical objects and processed them to create colour images. The preliminary Learning Progression (LP) focusing on inquiry skills and the results of the student project are highlighted.
\end{abstract}

Keywords

Astronomy Education — Image processing - Robotic Telescopes - Remote Telescopes Middle School Science

${ }^{1}$ Deakin University, Burwood, Victoria, Australia

${ }^{*}$ Corresponding author: ssalimpour@deakin.edu.au

\section{Introduction}

The beauty of the night sky is one of the most aweinspiring sights, the numerous points of light scattered across a seemingly infinite ocean of black, with the fuzzy white band of Milky Way majestically punctuating the blackness. Anyone who has had the opportunity to observe the night sky away from the suffocating lights of the city, can attest to this humbling and majestic experience.

Our eyes, despite their capabilities, are blind to some of the most fascinating objects contained within the observable Universe. Only sensitive to a sliver of the Electromagnetic (EM) Spectrum, called Visible Light, our eyes are ill-equipped to detect the spectrum of visual symphony produced by the myriad objects in the Universe - galaxies, nebula, clusters of stars, planets and much more. An excerpt of this symphony is seen in long exposure images of the night sky, revealing the astounding beauty and mystery hidden to our eyes.

The dawn of photography in the mid-19th century and its application to Astronomy (Osterman et al., 2007), opened our eyes to some very extraordinary, enigmatic and awe-inspiring vistas. Astrophotography is no longer limited to big research observatories. The affordability of telescopes, imaging cameras and easy access to software (Covington, 1999; Gomez and Fitzgerald, 2017; Han et al., 2018; Legault, 2014) has allowed amateurs to "Capture the Cosmos", or rather the objects it contains in 
astounding beauty. These images are not only aesthetically captivating, they are also scientifically rich. Although astrophotography started with the aim of recording scientific information from astronomical objects, it has serendipitously highlighted the innate aesthetics of astronomical objects.

The notion of astronomy as being a "Gateway Science" has been used to highlight how astronomy can be used to re-invigorate the science classroom, pique the curiosity of the students and engage them with science in general (NRC, 2001, 2011; Salimpour et al., 2018b, 2020). The richness and mystery of topics in astronomy provides a springboard into various concepts in science from basic motion to optics and beyond. Research has shown the positive classroom perceptions and knowledge changes that result from exposure to astronomy (Danaia et al., 2012, 2017), although, so far, there is some work to do to understand student attitude changes (Bartlett et al., 2018).

Over the past couple of decades, there has been a dramatic increase in Robotic and Remote telescopes, owing to the rapid progress and feasibility of technology (Gomez and Fitzgerald, 2017). However, despite this, the reviews by Salimpour et al. (2018a), show that within the school curricula, the use of Robotic/Remote telescopes (RRTs) is not explicit. The onus is on teachers to incorporate this into their lessons, given that most curricula afford the flexibility to incorporate lessons which make use of Robotic telescopes (RTs). However, as highlighted by (Cutts et al., 2018), the average science teacher lacks the knowledge required to guide students through such endeavours, and that teacher training is vital to ensure the consistent and successful implementation of RRT.

This paper provides an overview and results from an 11-week astronomy elective implemented in a Year 8 classroom at a non-governmental school in regional Victoria. A review of curricula from around the OECD, shows that middle school science curricula often include topics on light, colour and the basics of optics (Salimpour et al., 2020). This elective allowed those concepts to be taught within the rich and practical landscape of astronomical imaging. This is one example of using astronomy as a "Gateway Science”.

\section{Capturing the Light}

Since the first image of an astronomical object in 1858 by William Underwood, taken of Comet Donati (North, 2008), we have seen a fantastic expansion to our view of the Universe. In the early days, astronomical photography was aimed at capturing scientific data, rather than creating a striking image. Albeit, the images created were striking given that no one had ever seen these objects in this manner. The image of the Orion Nebula (M42) by Ainslee Common Figure 1 (Osterman et al., 2007), earned the Royal Astronomical Society's Gold Medal in 1884 (RAS, 1996). This image set the stage in what was to become a new age in astronomical observations. Astronomical images of that era although black \& white, carried a curiosity piquing quality, and aesthetic. Perhaps because they were never seen before, or the forms, shapes and patterns carry with them innate qualities that speak to our subconscious aesthetic.

In the mid 20th century, the image of the Andromeda galaxy (M31) by William C. Miller Figure 2 demonstrated the potential of astronomical colour photography (Miller, 1962). In the late 1970s, the work of David Malin at the Anglo-Australian Telescope, instigated the era of colour astrophotography both scientifically and aesthetically (Malin and Murdin, 1984; Malin et al., 1993). By combining images of astronomical objects taken on glass plates sensitive to different wavelengths of light, Malin was able to use dark room techniques to create striking colour images, that told the story of the physics at work. However, to the untrained eye, these images were awe-inspiring works of art in their own right.

The launch of the Hubble Space Telescope (HST) in 1990 and the images produced via its myriad of instruments over the decades, took colour imaging to an entirely new level. Bringing to the public, mesmerizing views of the Universe that their eyes could not see and their imagination could not synthesize. The colour images of David Malin and the HST image processing team revealed that the Universe 
Capturing the Cosmos: Teaching Astronomy (and more) through Astrophotography in Middle School $-3 / 18$

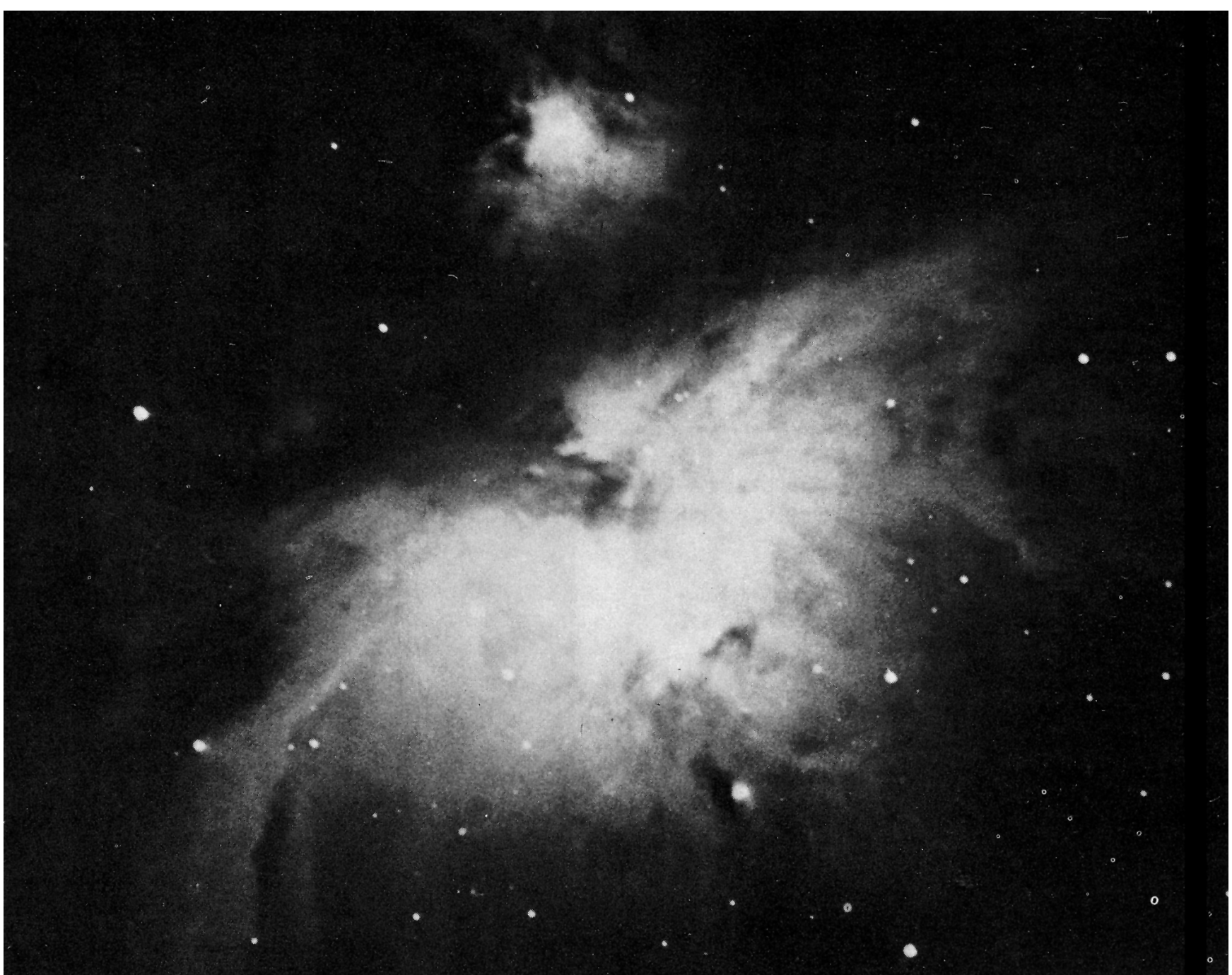

Figure 1. Orion Nebula image taken by Ainslee Common in 1883. Image credit: (Malin et al., 1993) 


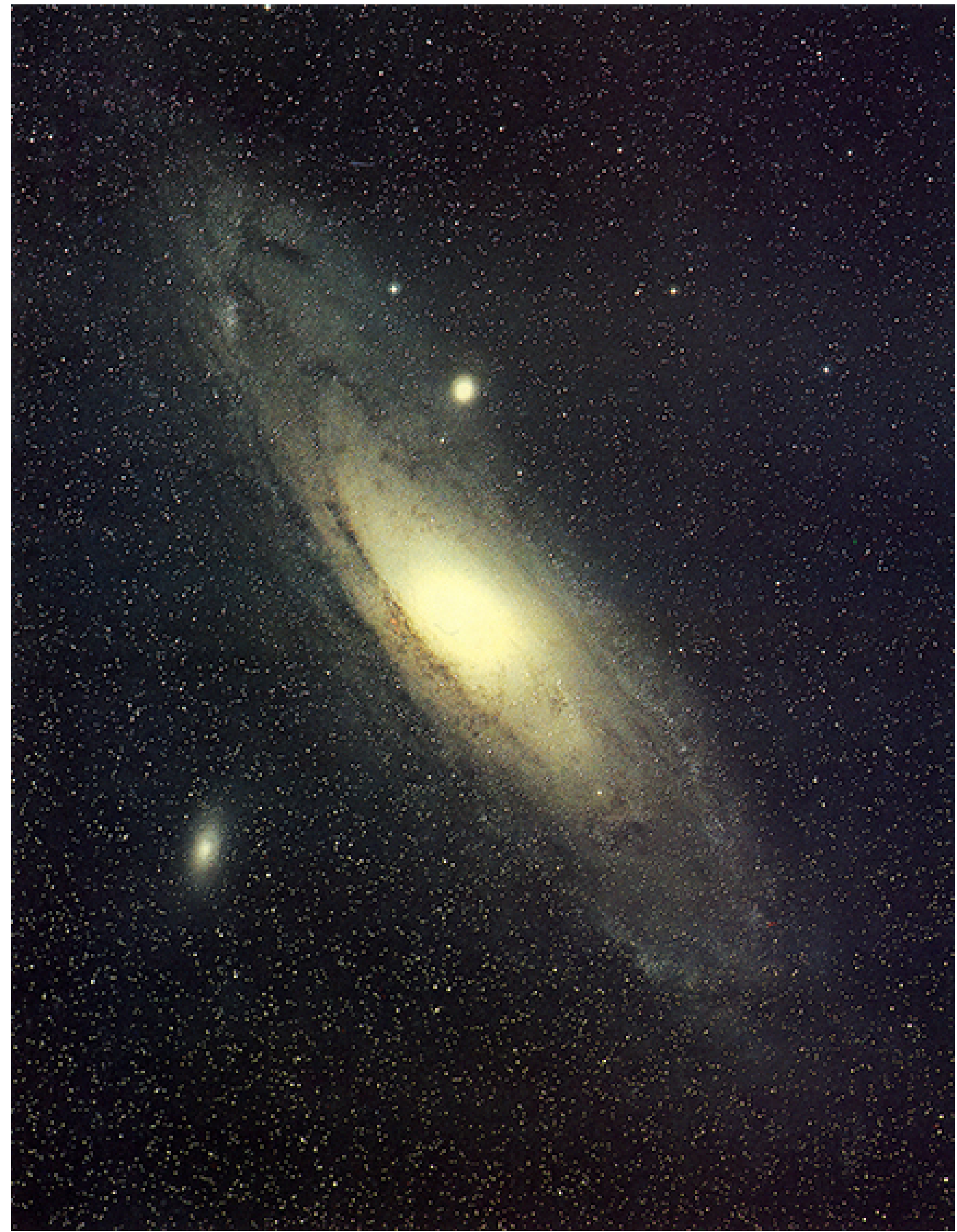

Figure 2. The first ever true colour-corrected image of M31. Image credit: (Malin et al., 1993) 
is not a dark cold place, rather, it is permeated with rich, dynamic objects, exhibiting intricate forms and a symphony of colours hidden to our limited eyes.

In the past couple of decades, the increasing affordability of telescopes and imaging cameras has brought deep sky-imaging within the reach of amateurs, who create both aesthetically pleasing and scientifically rich images (RMG, 2017). These images, although requiring hours of work, are based on the same fundamental principles used by Malin, and the HST. Therefore, they provide fertile ground to expound the fundamental science they encapsulate in the science classroom.

\section{Science, Art, or Both?}

One aspect of astronomical images that is shared by everyone, is the beauty and mystery invoked when looking at these images. The beauty of an image is closely linked to the notion of aesthetics; however, aesthetics is nontrivial, complex and multi-faceted, rooted in philosophy and culture, both subjective and objective (Wickman, 2006). Engaging in a debate about aesthetics is beyond the scope of this paper, suffice to say that looking at images of galaxies and nebulae invokes an aesthetic experience both visually and psychologically. This experience is often global, which is judged by the prevalence in media attention afforded to astrophotography competitions.

There is a growing movement in education research to find ways in using aesthetics to re-invigorate school science in the 21st century (Lemke, 2001; Watts, 2001; Wickman, 2006). The idea of aesthetics in education while not novel (Dewey, 2005), has yet to be effectively implemented in science education. This is perhaps owing to the stereotypical binary that is propagated about Art and Science, ergo, by extension aesthetics is seen as related to Art rather than Science. This distinction goes back to the late 18th century and Kant (1931), with his proposition of Pure reason, Practical reason and Aesthetics. However, at a fundamental level there is no distinction (Root-Bernstein, 1989).

Over past few years, there has been a growing movement towards the integration of Art in STEM, leading to STEAM (Science, Technology, Engineering, Art, Mathematics) (Herro and Quigley, 2016; Kim and Bolger, 2017; Liao, 2016; Pomeroy, 2012; Zevin et al., 2015). The novelty of STEAM has instigated different reports (Kim and Park, 2012; Pomeroy, 2012; Zevin et al., 2015). Despite this, there are no empirically researched pedagogical strategies that demonstrate the effective integration (Herro and Quigley, 2016). It is worth mentioning that the intergration of disciplines into currricula is not new. The notion of an "integrated curriculum", which is what the whole STEM, STEAM movement echoes goes back 1970s (Bernstein, 1975; Pring, 1971).

During the 1980s and 90s, the Freyberg Integrated Studies project aimed at bringing innovation to curriculum and pedagogy (McKinnon et al., 1991). This decade marked the start of thematic, integrated approaches to curriculum, which saw a growing interest in incorporating integrated units of work (Lipson et al., 1993). An example was reported in Australia with the 1996 review of the New South Wales (NSW) Science Curriculum, wherein, primary teachers wanted integrated units of work in science (McKinnon 2017, personal communication). The problems with curriculum integration has been highlighted by (Mason, 1996), who highlights some of the motivation behind the support for curriculum integration: Psychological/developmental, Sociocultural, Motivational and Pedagogical. The problems identified include: Trivialisation, Assessment, Skills, Teacher knowledge, and School structure.

One could perhaps deduce that the notion of STEAM as implemented in the classroom, is to a degree governed by the "teacher's style and epistemologies".

This elective draws on the notion of aesthetics as the foundation to teach fundamental concepts in astronomy. It builds on aesthetics not only in terms of visual beauty, but rather, aesthetics in terms of experiences (Wickman, 2006). Using aesthetics provides an impetus to explore the science, by taking students on an experiential journey which they can relate to, that of beauty, mystery and discovery. 


\section{Development of Preliminary Learning Progression}

Learning Progressions (LPs) have become prevalent in science education (Alonzo and Gotwals, 2012) and have gained popularity in astronomy education research (AER) (Colantonio et al., 2018; Plummer and Maynard, 2014; Testa et al., 2015). Despite their potential for being valuable to science education, there are some cautions, such as the premature imposition of constraints on instruction (Shavelson and Kurpius, 2012), if LPs are under-researched they lead to reinforcing naïve conceptions (Shavelson and Kurpius, 2012), the need for professional development for teachers (Shavelson and Kurpius, 2012), LPs should be tested in a variety of classrooms to determine that they are working as intended (Krajcik, 2012) and most importantly researchers must be critical of their work by avoiding "force fitting data" to the LPs (Krajcik, 2012). Good LPs require extensive validation to ensure they are empirically valid (Plummer, 2012). Although there are varied definitions of LPs, in general they provide a roadmap for the gradual sophistication in knowledge and skills in learners as they move from naïve notions to expert notions in the learning process (Alonzo and Gotwals, 2012). Stages in LPs do not necessarily follow the knowledge levels as explicated by the discipline, given that the focus is on a developmental approach (Piaget and Cook, 1952) and how students reason when presented with new ideas (Alonzo and Gotwals, 2012).

The development of the LP for this elective was based on a Design-based approach cycle (Collective, 2003), of multiple implementations over a period of three years. Initially, a theoretical LP was developed by reviewing literature on AER, filtering out some of the key concepts with which students have difficulty, and determining how those concepts fit into the Big Idea Goal (BIG), which is related to astronomical imaging. This allowed three overarching themes to be synthesized:

1. Basics

2. Objects in the Universe

3. Image processing
Basics dealt with the theoretical minimum that students would need, to be able to pick objects based on their location and time of year. It is aimed at understanding celestial motions from a geocentric reference frame, based on what they can observe. Objects in the Universe, was aimed at familiarizing students with the various types of objects in the Universe and their characteristics, thereby allowing students to identify those objects. Image processing, was aimed at showing students the process of colour image creation, familiarizing them at a conceptual level with the mathematical principles of image processing. In addition, this section included tutorials on using the required software.

The above framework was used to develop a preliminary hypothetical LP, which was then refined to be in its current form, as shown in Table 1. It is presented as a potential road map into how students moved to higher levels of sophistication in terms of their content knowledge and skills, in the context of the BIG. The LP uses the content capital that students bring into the classroom as the basis for creating conceptual change through gradual levels of sophistication, whereby each level provides them with new insights to question their preconceived ideas.

\section{Elective Design and Implementation}

Although in the Australian Middle School curriculum (Year 7-9), this elective does not explicitly address any of the curriculum statements, it does provide a context for teaching concepts of light, the notions of matter, and working with real scientific data. Looking at the Next Generation Science Standards (NGSS, 2018)), this elective has the potential of being used to introduce or extend the concept of Electromagnetic Radiation PSB4.

The elective was designed using material from Our Solar Siblings (Fitzgerald et al., 2018) and modified to work within the timeline and the abilities of the students. Students were in Year 8, at a nongovernmental school in regional Victoria, Australia. The elective consisted of two 55 minute lessons per week, extending over a single term of 11 weeks, 
although in reality accounting for all the classes, it was around 9 weeks. The class consisted of 12 students (10 girls, 2 boys). Students arrived into the class with exposure to popular media topics on astronomy and the usual curious questions about black holes, aliens, the size of the Universe and the fate of the Universe.

A concept inventory - The Astronomy Knowledge Questionnaire (Lazendic-Galloway et al., 2017), coupled with in-class discussions, was used as a formative assessment tool to determine the conceptual and content knowledge of students. The results revealed that the majority of students, albeit familiar with some terminology in astronomy, had very limited knowledge on astronomical concepts, and held misconceptions, with regards to seasons, phases of the Moon, motion of stars, and astronomical images. Based on the results, the elective was designed in such a way as to not only address some of those misconceptions, rather, augment the student's knowledge in astronomy.

Students were provided with some introduction to astronomy via Socratic questioning (Elder and Paul, 1998). Where the task was to scaffold the students in exploring different concepts. This provided the stage for an inquiry-based approach, by integrating the student's content capital into the discussions and using that as a conduit to guide them to valid scientific conceptions.

The next step was to use a "Big Idea" concept to set the stage for the remainder of the elective. Big ideas are defined as concepts/questions/statements which have far-reaching implications (NRC, 2007), and deep explanatory power (Smith et al., 2004). Selecting a "Big Idea" in astronomy can be challenging (Plummer, 2012), and requires extensive investigation. However, given the limited time, the approach was to pick a topic to which the students already had a vast amount of exposure and could be implemented via RTs in the classroom - astronomical imaging was the logical pathway. This step allowed us to synthesize a Big Idea Goal (BIG), by taking the traditional Big Idea notion and making it into a practical outcome, that students aimed to achieve. For this elective the BIG was synthesized as: "I want to create a "pretty" colour image of an astronomical object". This led to the students to ask:

- What skills do I need to learn?

- What theoretical knowledge do I need?

- What tools would I need?

- What do I already know about astronomical imaging?

- What object do I choose?

- How do I know what object to choose?

Activities chosen from the Our Solar Siblings Project 1 (Fitzgerald et al., 2015), were used to facilitate the learning of theoretical concepts, which included learning about the various objects in the Universe and initial concepts about the Universe. Following some interactive lessons on Celestial Mechanics using Stellarium, basic optics and familiarizing students with the instruments they would be using to capture their images, students were asked to pick five objects that they would like to image. A GoogleForm was created to facilitate student selections, which were then queued via the LCO Observations portal.

While waiting for the images, students were introduced to the basics of imaging and image processing, starting with the Electromagnetic Spectrum and the physiology of the human eye. They were then introduced to FITS Liberator and Adobe Photoshop. The use of FITS liberator, allowed for a conceptual explanation of the idea behind stretching images, and how this was achieved using mathematical functions. A small activity was designed to get students practicing these skills by trying to create colour images using images from the Hubble Space Telescope Legacy Archive.

\section{Results}

The students worked in pairs or individually, in total 6 different objects were imaged, some students picked the same object; however, with different exposure times. The objects were: NGC5128 (Centaurus A); NGC5139 (Omega Centauri); M17 (Omega Nebula); NGC 4567/NGC 4568 (Siamese Twins); M41; M51(Whirlpool galaxy). Two images were standouts Figure 3 and Figure 4, especially because 
Capturing the Cosmos: Teaching Astronomy (and more) through Astrophotography in Middle School - 8/18

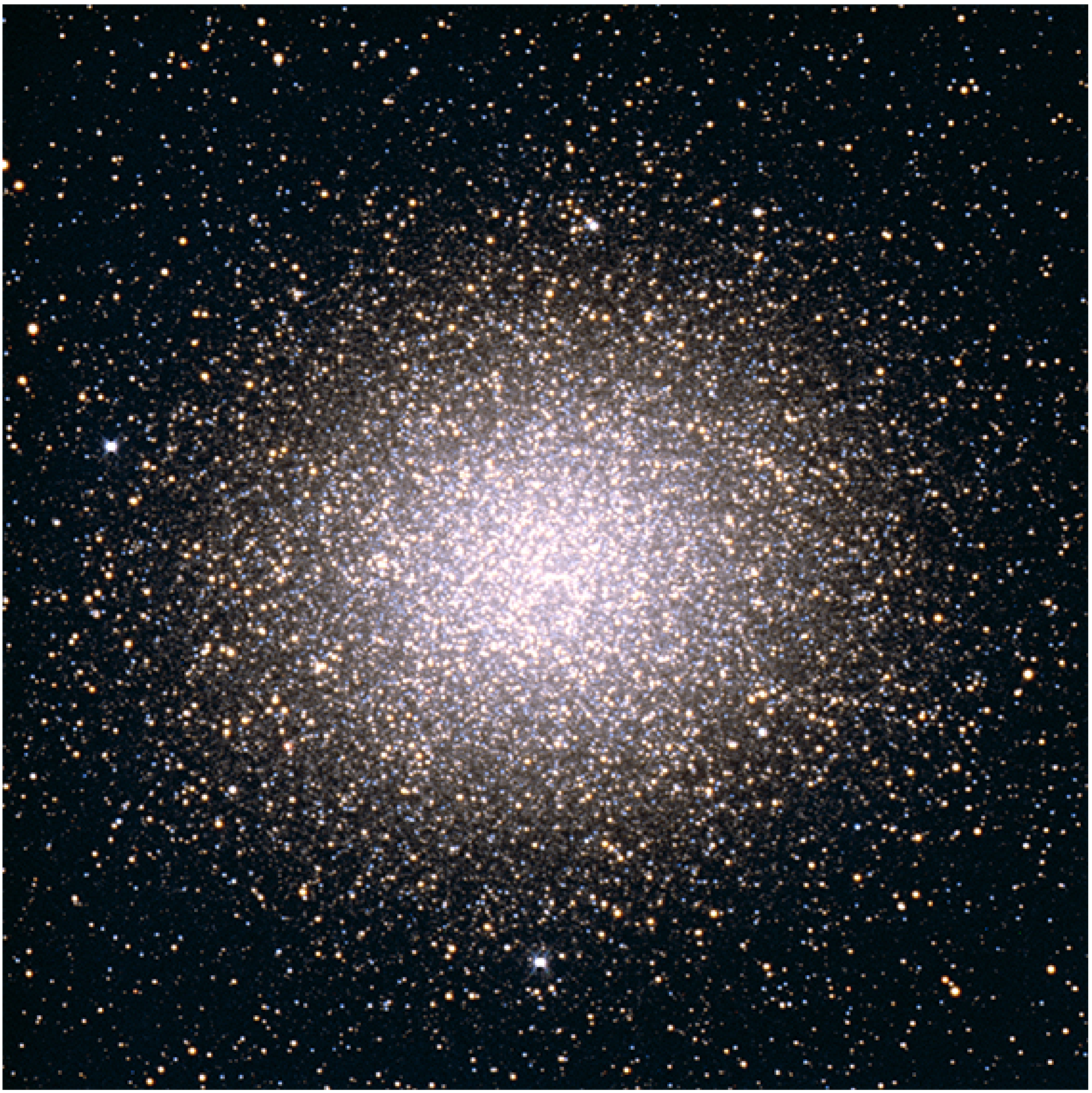

Figure 3. Colour image of Omega Centauri (NGC5139). Notice how the processing has revealed the colour of the stars in the cluster 


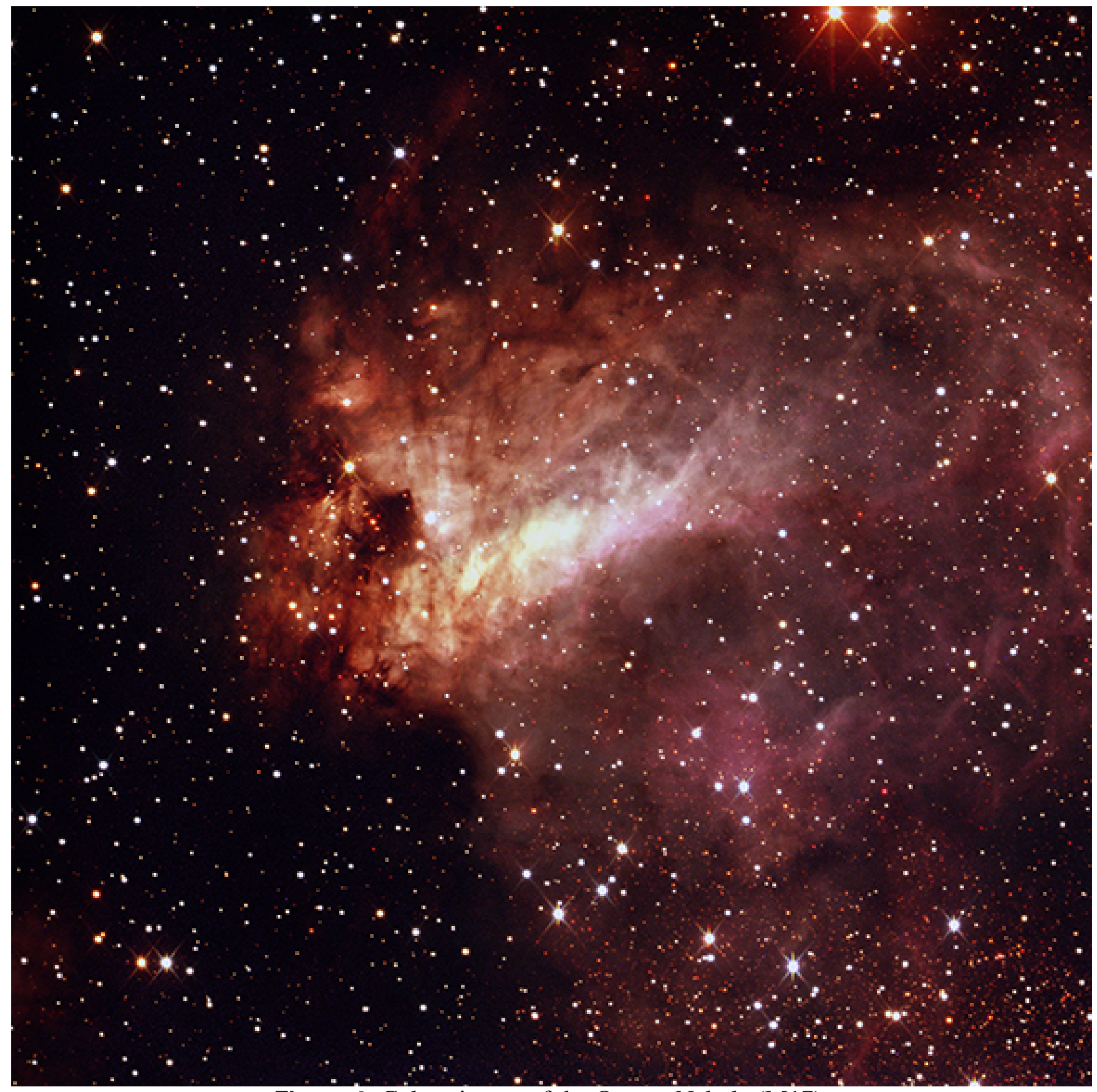

Figure 4. Colour image of the Omega Nebula (M17). 
the students who processed them had no previous exposure to astronomical imaging and only limited exposure to basic astronomy in primary school.

One aim of this elective from an educational perspective was to explore how to tap into the power of RRTs in Middle School to teach various concepts in astronomy, by highlighting the underlying physics and mathematics in the context of astronomical imaging and image processing. Furthermore, it was about showing the synergy that exists between Science and Art, and how this synergy can be practically applied in the classroom. This can be achieved by unpacking the notion of aesthetics and aesthetic experiences (Wickman, 2006). Without creating a binary between Art and Science in the classroom.

The BIG gave students a tangible outcome, they wanted to create "pretty pictures", which although requires technical skills, also requires knowledge from various domains in Physics. Students had to learn this knowledge at the theoretical and practical minimum, which meant that they found a direct application of this knowledge to the BIG. The BIG also set the stage for a true integration of Art and Science, by drawing on the commonality that both share: observation, experimentation, deduction, inference, discovery and beauty from the lens of both discipline and aesthetics.

In-class observations highlighted the excitement that students experienced when they changed the blending mode of the layers in Photoshop, thus mixing the layers and revealing the colour image. This was truly a surprise to them and in many ways a discovery in the broadest sense of the word. Discussions with the students revealed that this surprise was owing to the sense of not knowing what their images would look like, and the lack of confidence they had in themselves. This raises a valuable insight. True scientific discovery is not about knowing the "correct" answer, rather it is about discovering that the knowledge and skills you have could be used to generate new knowledge. Although students had seen the images published on the internet, with a myriad of colour palettes, they did not anticipate that they had the acquired knowledge to create the same image. Although it is worth noting that when students compared their images with those on the internet, some were discouraged as to why their images were not the same as those. They questioned whether their images were poor, or the images on the internet were fake. This opened the discussion into the discrepancy, which led to deeper discussions about colour, filters, and telescopes.

Secondly, it highlights the power of ownership, although the students were excited when they used archived images in the practice run, knowing that this image was created by them, brought with it vastly different level of motivation. Research into the concept of ownership, and how that affects student learning, has yet to be studied in detail.. However, there is a professional general consensus that it seems to s have an impact (Gould et al., 2006; McKinnon and Geissinger, 2002; McKinnon et al., 2002). Anecdotal evidence from this elective hints at ownership having a positive impact on student motivation and learning. Although a deep empirical study is required to explore these findings.

Looking at their images, the students, in addition to using terminology innate to the Arts to describe their images, now could explain the Physics behind what was occurring in the image. They could now articulate the "beauty of the science" in their images. One could argue that this is one implementation of STEAM in classroom, or more specifically an integrated curriculum.

One interesting observation was the challenge that certain students had with being given the freedom to make choices. Discussions with the students revealed that this is potentially owing to the fact that most of middle school science is based around recipe-based experiments. Whereby the students aim to get the "correct" answer by following the instructions given by the teacher. They are also good at searching the internet to do "research" when writing an essay or report, however, they are hesitant to venture into the unknown, using only their current knowledge as a guide. These students are not in the top $10-20 \%$, nor in the bottom $10-20 \%$, they are the middle band, which are often easily discouraged and include students with a variety of abilities and levels.

Based on anecdotal observations, this is in essence, attributed to self-efficacy. There has been research 
in educational psychology with regards to the effects of self-efficacy on teaching and learning (Bandura, 1982; Britner and Pajares, 2006; Greene, 2017; Schoon and Boone, 1998; Settlage et al., 2009; Zimmerman, 2000) and also the effects of emotions in science education (Bellocchi et al., 2017; Sinatra et al., 2014). One can also invoke the notion that aesthetic experiences can have wide ranging impacts on how students learn (Wickman, 2006). Although students may be excited by topics in astronomy (e.g.: blackholes, exoplanets), and inspired by the images they see in the media, this does not necessarily equate to higher levels of self-efficacy in all students when they are tasked with an inquirybased learning task. Therefore, it is vital to embed activities that enhance student self-efficacy, before embarking on such open-ended inquiry tasks, especially when students have had little or no exposure.

\section{Discussion}

The implemenation of the teaching sequence was based on:

- Teaching students the theoretical minimum.

- Allowing students to experiment with sample data

- Students imaging and processing their astronomical object of choice

One of the stages in the elective was teaching students the relevant software, students were provided with sample images from the Hubble Space Telescope Legacy Archive. This provided them with a context to learn how to use the both FITS Liberator and Adobe Photoshop. To reduce the cognitive load on students, and familiarise them with using the software, tutorial videos were made showing:

- How to install FITS Liberator, and check that Adobe Photoshop was installed (This was because the school had a site license to Adobe Creative Cloud

- How to use FITS Liberator

- How to use Adobe Photoshop

- How to create a colour image using sample data
The use of the tutorial videos meant that troubleshooting installations was kept to the bare minimum, and was done via email outside of class time. This allowed class time to be spent on discussions around the fundamentals behind imaging, the physics, and the use and theory of colour. The images students created with the HST Legacy data, were used as a content for discussions. This draws on the work done in the context of colour imaging and the aesthetics of astronomical images (Rector et al., 2017) and (Smith et al., 2015).

\section{Why does my image look different?}

Students when working on creating colour images with the data(images) they obtained using the robotic telescopes, found it challenging and at times discouraging when their images were quite different than those found on the internet. This was further complicated in instances when students with the same two images had different end results.

Some students intentionally decided to go with a particular colour palette, which was guided by how they interpreted the various aspects of the object being imaged. They discovered by experimenting with variations in the Hue, or reversing the image.

In order to address this stage in the learning, classroom discussions were based on scaffolding students through a series of questions, which required:

- Students explicitly identifying the visual differences between their images and those they had found.

- Students comparing the instruments, filters, software, exposure used for each image

- Students determining the goal of each image.

The above led to discussions about the underlying concepts, some of the key ideas that were put forward by students included:

- The way the images were stretched in FITS Liberator

- The exposure time for the images

- The resolution of the telescope

- The field of view of the CCD

- The way colour correction was implemented in Photoshop, post standard steps 
Table 1. Proposed LP for Astronomical Imaging

\begin{tabular}{|c|c|}
\hline Level & Skill/Knowledge \\
\hline 4 & $\begin{array}{l}\text { - Determining the best exposure for images by taking into consideration the nature of the object, } \\
\text { apparent magnitude of the object, the sensitivity of the instrumentation and the filters being } \\
\text { used } \\
\text { - Applying stretch functions with an aim of highlighting key features } \\
\text { - Combining images taken in various filters to create a colour image of an astronomical object } \\
\text { - Making independent decisions about colour palette and the goal of the image }\end{array}$ \\
\hline 3 & $\begin{array}{l}\text { - Selecting astronomical objects for imaging by taking into consideration the visibility of the } \\
\text { object at a particular time of year from a particular location } \\
\text { - Determining whether an astronomical object selected for imaging will fit in the telescope } \\
\text { Field-of-View (FoV), by taking into consideration the angular size } \\
\text { - Understanding the various objects in the Universe and their characteristics }\end{array}$ \\
\hline 2 & $\begin{array}{l}\text { - Understanding the motions of celestial objects in the context of Right Ascension (RA) and } \\
\text { Declination (DEC) } \\
\text { - Understanding that Right Ascension (RA) and Declination (DEC) are a geocentric coordinate } \\
\text { system } \\
\text { - Understanding the relationship between degrees, arcminutes and arcseconds }\end{array}$ \\
\hline 1 & $\begin{array}{l}\text { - Understanding the magnitude system in astronomy } \\
\text { - Understanding the fundamental workings of the human eye and how it relates to imaging } \\
\text { - Understanding that the human eye can only see in a small wavelength range, called the Visible } \\
\text { - Spectrum } \\
\text { - Understanding the workings of telescopes in terms of light and optics } \\
\text { - Understanding the workings of CCDs, and how they capture images } \\
\text { - Understanding the theory of colour, its use and the physics behind colour } \\
\text { - Understanding the software used to process images }\end{array}$ \\
\hline Entry & $\begin{array}{l}\text { - Belief that astronomical images viewed in the media are taken in colour } \\
\text { - Belief that astronomical images are computer generated graphics and not real } \\
\text { - Belief that astronomical objects can be imaged at any time of the year } \\
\text { - Inaccurate understanding that all objects imaged will be large as seen in the media }\end{array}$ \\
\hline
\end{tabular}


- The purpose of the image being education, science or just pushing the boundaries of image processing

\section{Ownership}

The power of ownership was evident once the students were given printed copies of their images. Students, even those who had found it challenging, and at first were not happy with the images they created, were delighted to see their images in print. They commented on the fact that they had created the image, and were proud to display it at home, or their parents would frame the image. This is an important aspect of authentic experiences, whereby students found purpose in the work they were doing, and especially because they were making decisions, and at times learning that their decisions did not have the predicted outcome. The idea of ownership started with the fact that they had to learn how to use the software through videos, there was no direction instruction by the instructor, rather just troubleshooting and conceptual guidance. This grew, evolved and was nurtured because they ultimately had to make some challenging decisions when picking their targets and processing the images.

\section{Reflections on the Learning Progression}

This LP for astronomical imaging in Table 1 was developed over a period of time via various cohorts, and so was guided by the implementation of colour imaging in the classroom. A learning progression by its very nature is guided and developed by instruction, interaction with students' prior knowledge and construction of new knowledge. It should be emphasised that the LP presented here is not a teaching sequence, it can be used to develop a teaching sequence, or guide curriculum development. The LP shows at what level of sophistication each of the various skills and knowledge are when it comes to astronomical colour imaging in the classroom. At any given stage, in the reality of the classroom there will be students at various levels of the learning progression.

Although this LP is presented as one coherent progression, it encapsulates two pathways: a) Target selection and b)Making a colour image. Al- though, some would argue that it needs to be two LPs, we argue based on experience that to implement a coherent elective, they need to be merged, as this is vital to delivering an authentic experience.

Furthermore, this LP takes a mid to coarsegrained approach (the level of detail), this is because the aim was to determine the theoretical minimum that is required for students to engage in authentic image processing. If a fine-grained approach were taken, then it would make sense to split the learning progression into the two pathways stated above.

At the start of the project students asked six questions, which can be linked to the levels of the LP:

\section{What skills do I need to learn?}

This is addressed throughout the learning progression, because there are a range of skills at various levels of sophistication. For example, skills in image processing, or rather using the software. Students start with the basics in Level 1, but by Level 4 they understand the intricacies of image processing at their developmental level, and in the context of this elective.

\section{What theoretical knowledge do I need?}

Theoretical knowledge exists at various levels from understanding celestial motions, to the instrumentation, the objects in the Universe, their characteristics, the theory behind image processing, and the theory of colour.

\section{What tools would I need?}

This is addressed in Level 1, it is really about introducing students to telescopes, cameras and the software. Taking a fine-grained approach, one could zoom into each of the skills, however, the aim is to identify the key skills and knowledge that are attainable at the developmental stage of a middle school student with no background in astronomy.

\section{What do I already know about astronomical imag- ing?}

This is addressed mainly in the Entry stage where the teacher through discussion has the opportunity to gain insights into students conceptions. 
What object do I choose?

\section{How do I know what object to choose?}

These two questions are addressed in Levels $\mathbf{2}$ and

3. It requires not only knowledge of celestial motion, but also the types of objects and the specifications of the telescope.

Level 4 in the LP is where students can independently engage in astronomical colour imaging. In essence it brings together all the fundamentals from preceding levels.

It must be emphasized that the BIG was to make "pretty" pictures, which carries with it a subjective aesthetic, yet a global aesthetic experience. This latter experience is at the heart of science. The aesthetic experience of taking Black \& White images, and creating a colour image, is a positive aesthetic experience. Unlike the positive aesthetic experience, which must be learned through disciplinary knowledge, e.g. the beauty in a mathematical equation, the aesthetic experience afforded by a colour astronomical image is universal (Wickman, 2006) for those not visually impaired.

The LP utilised in this study is hypothetical and as such requires further refinement. This approach is in the process of being adapted into an empirically validated LP, which provides teachers with a roadmap to one avenue of implementing RRTs in a middle school science classroom. The LP will also provide curriculum developers with a framework on connecting concepts across disciplines and embedding the practical applications of concepts into the curriculum statements.

\section{Conclusion}

The beauty of the Universe can be appreciated by everyone irrespective of their culture, religion or political persuasion. An image of a galaxy, nebula, or even a nightscape showing the Milky Way, invokes experiences that go beyond the visual aesthetics of the image, instigating a journey through the Universe and discussions of its mysteries. Student engagement in school science is ebbing, this has instigated educators and policy makers to seek ways in bringing about a change. Astronomy, with its richness of topics and awe-inspiring visuals is suited to instigate this change - a "Gateway Science". Astronomy automatically instigates discussions about the mysterious and the awe-inspiring. Most students let their imagination run wild when asking questions, conjuring up scenarios, which often can be answered using our current knowledge and drawing on the students' pre-existing knowledge. With this in mind, a Year 8 elective was implemented that allowed the students to use RRTs to capture images of astronomical objects they found interesting, and combine those images to create a "pretty" colour image. This elective is but one example of how astronomy can be used in teaching core science concepts, using a single Big Idea Goal, which is tangible and familiar to students.

Some interesting insights gleaned from this study revealed:

- The challenge experienced by certain students in making choices, especially those who are accustomed to being given recipebased experiments in school science

- The surprise and excitement experienced by students when they first glimpsed the colour image they had created

- The discrepancy in quality between their own images and those published on the internet was a source of despair

- The constant need for some students to be told whether their image was "good"

- The combined use of art and science terminology by the students to describe their image

We appreciate and emphasise that there is much work that needs to be done in developing this LP (Krajcik, 2012; Shavelson and Kurpius, 2012). Therefore, we present this LP as a starting point. The next stage will be an empirical validation of the preliminary LP developed and implemented in this elective, which will provide a roadmap for curriculum developers and interested teachers in bringing engaging science into the middle school science classroom using RRTs. This brief case study highlights the enormous potential that astronomical imaging using RRTs has on teaching in the classroom, and how they can be easily connected to current curriculum topics. 
Furthermore, it demonstrates how Arts can be integrated with Science, in a practical classroom setting, without jeopardizing either discipline, rather, drawing on the commonalities of each discipline. This synergy further supports the consensus that astronomy can truly be considered a "Gateway Science", maybe it is also a "Gateway to Learning".

\section{Acknowledgements}

I would like to thank the organizers of the RTSRE Conference for affording me the opportunity to present this work. In addition, my thanks to Dr. Michael Fitzgerald and Prof. David McKinnon for their never-ending support and helpful comments in preparing this paper. I would also like to thank Las Cumbres Observatory for the time on their telescopes. And finally a big thanks to our Hawai' ian hosts (Tim and Stephanie Slater) for making this conference extremely welcoming.

\section{References}

Alonzo, A. C. and Gotwals, A. W. (2012). Learning progressions in science: Current challenges and future directions. Springer Science \& Business Media.

Bandura, A. (1982). Self-efficacy mechanism in human agency. American psychologist, 37(2):122.

Bartlett, S., Fitzgerald, M. T., McKinnon, D. H., Danaia, L., and Lazendic-Galloway, J. (2018). Astronomy and science student attitudes (assa): A short review and validation of a new instrument. Journal of Astronomy \& Earth Sciences Education-June, 5(1).

Bellocchi, A., Quigley, C. F., and Otrel-Cass, K. (2017). Emotions, aesthetics and wellbeing in science education: Theoretical foundations. In Exploring emotions, aesthetics and wellbeing in science education research, pages 1-6. Springer.

Bernstein, B. B. (1975). Class, Codes and Control [v. 3]: Towards a Theory of Educational Transmissions; [by] Basil Bernstein. Routledge and Kegan Paul.
Britner, S. L. and Pajares, F. (2006). Sources of science self-efficacy beliefs of middle school students. Journal of Research in Science Teaching: The Official Journal of the National Association for Research in Science Teaching, 43(5):485499.

Colantonio, A., Galano, S., Leccia, S., Puddu, E., and Testa, I. (2018). Design and development of a learning progression about stellar structure and evolution. Physical Review Physics Education Research, 14(1):010143.

Collective, D.-B. R. (2003). Design-based research: An emerging paradigm for educational inquiry. Educational Researcher, 32(1):5-8.

Covington, M. A. (1999). Astrophotography for the Amateur. Cambridge University Press.

Cutts, K. R., James, C. R., Miller, S., Danaia, L., and et al (2018). Astronomy student research in the international baccalaureate. RTSRE Conference Proceedings, June 2017, San Diego California.

Danaia, L., McKinnon, D. H., and Fitzgerald, M. (2017). Ideal pictures and actual perspectives of junior secondary school science: comparisons drawn from australian students in an astronomy education programme. Research in Science \& Technological Education, 35(4):445-460.

Danaia, L., McKinnon, D. H., and Parker, Q. (2012). Space to grow: Lcogt. net and improving science engagement in schools. Astronomy Education Review.

Dewey, J. (2005). Art as experience. Penguin.

Elder, L. and Paul, R. (1998). The role of socratic questioning in thinking, teaching, and learning. The Clearing House, 71(5):297-301.

Fitzgerald, M., McKinnon, D. H., and Danaia, L. (2015). Inquiry-based educational design for large-scale high school astronomy projects using real telescopes. Journal of Science Education and Technology, 24(6):747-760. 
Fitzgerald, M. T., McKinnon, D. H., Danaia, L., Cutts, R., Salimpour, S., and Sacchi, M. (2018). Our solar siblings: A high school focused robotic telescope-based astronomy education project. $R T$ SRE Conference Proceedings, June 2017, San Diego California.

Gomez, E. L. and Fitzgerald, M. T. (2017). Robotic telescopes in education. Astronomical Review, 13(1):28-68.

Gould, R., Dussault, M., and Sadler, P. (2006). What's educational about online telescopes?: Evaluating 10 years of microobservatory. Astronomy Education Review, 5(2).

Greene, B. A. (2017). Self-Efficacy and Future Goals in Education. Routledge.

Han, J., Wang, C., Fan, D., Cui, C., Li, S., Mi, L., Li, Z., Xu, Y., He, B., Li, C., et al. (2018). Amateur public observatory i: The observatory and hardware integration system. Astronomy and Computing.

Herro, D. and Quigley, C. (2016). Innovating with steam in middle school classrooms: Remixing education. On The Horizon, 24(3):190-204.

Kant, I. (1931). Critique of Judgement. Macmillan London.

Kim, D. and Bolger, M. (2017). Analysis of korean elementary pre-service teachers' changing attitudes about integrated steam pedagogy through developing lesson plans. International Journal of Science and Mathematics Education, 15(4):587605.

Kim, Y. and Park, N. (2012). The effect of steam education on elementary school student's creativity improvement. In Computer applications for security, control and system engineering, pages 115-121. Springer.

Krajcik, J. S. (2012). The importance, cautions and future of learning progression research. In Learning Progressions in Science, pages 27-36. Springer.
Lazendic-Galloway, J., Fitzgerald, M., and McKinnon, D. H. (2017). Implementing a studiobased flipped classroom in a first year astronomy course. International Journal of Innovation in Science and Mathematics Education (formerly CAL-laborate International), 24(5).

Legault, T. (2014). Astrophotography. Rocky Nook, Inc.

Lemke, J. L. (2001). Articulating communities: Sociocultural perspectives on science education. Journal of research in science teaching, 38(3):296-316.

Liao, C. (2016). From interdisciplinary to transdisciplinary: An arts-integrated approach to steam education. Art Education, 69(6):44-49.

Lipson, M. Y., Valencia, S. W., Wixson, K. K., and Peters, C. W. (1993). Integration and thematic teaching: Integration to improve teaching and learning. Language Arts, 70(4):252-263.

Malin, D. and Murdin, P. (1984). Colours of the Stars. CUP Archive.

Malin, D., Murdin, P., and Malin, D. (1993). Colours of the Galaxies. Promotional Reprint Company.

Mason, T. C. (1996). Integrated curricula: Potential and problems. Journal of teacher education, 47(4):263-270.

McKinnon, D. H. and Geissinger, H. (2002). Internet astronomy in schools using remotely controlled telescopes. In Tien, D., editor, 1st International conference on Information Technology and Applications, ICITA 2002, pages 1-5. Institute of Electrical \& Electronics Engineers.

McKinnon, D. H., Geissinger, H., and Danaia, L. (2002). Helping them understand: Astronomy for grades 5 and 6. Information Technology in Childhood Education Annual, 2002(1):263-275.

McKinnon, D. H., Nolan, P. C., Openshaw, R., and Soler, J. (1991). New zealand curriculum innovation in historical and political context: The 


\section{Capturing the Cosmos: Teaching Astronomy (and more) through Astrophotography in Middle \\ School $-17 / 18$}

freyberg integrated studies project and parallel projects of the 1940s. J. Curriculum Studies, 23(2):155-175.

Miller, W. C. (1962). Color photography in astronomy. Publications of the Astronomical Society of the Pacific, 74(441):457-473.

NGSS (2018). Next generation science standards.

North, J. (2008). Cosmos: an illustrated history of astronomy and cosmology. University of Chicago Press.

NRC (2001). The Role of Astronomy Education. The National Academies Press.

NRC (2007). Taking science to school: Learning and teaching science in grades $K-8$. National Academies Press.

NRC (2011). New Worlds, New Horizons in Astronomy and Astrophysics. The National Academies Press.

Osterman, M., Stuart, N., Peres, M., Frey, F., Lopez, J., Malin, D., Huxlin, K., and Williams, S. (2007). The focal encyclopedia of photography: digital imaging, theory and applications history and science. Burlington: Focal Press.

Piaget, J. and Cook, M. T. (1952). The origins of intelligence in children. WW Norton \& Co.

Plummer, J. D. (2012). Challenges in defining and validating an astronomy learning progression. In Learning progressions in science, pages 77-100. Springer.

Plummer, J. D. and Maynard, L. (2014). Building a learning progression for celestial motion: An exploration of students' reasoning about the seasons. Journal of Research in Science Teaching, 51(7):902-929.

Pomeroy, S. R. (2012). From stem to steam: Science and art go hand-in-hand. Scientific American. Visit https://blogs. scientificamerican. com/guest-blog/from-stem-to-steamscienceand-the-arts-go-hand-in-hand/(Erişim, Nisan 2017).
Pring, R. (1971). Curriculum integration. Journal of Philosophy of Education, 5(2):170-200.

RAS (1996). Winners of the gold medal of the royal astronomical society.

Rector, T. A., Levay, Z. G., Frattare, L. M., Arcand, K. K., and Watzke, M. (2017). The aesthetics of astrophysics: How to make appealing colorcomposite images that convey the science. Publications of the Astronomical Society of the Pacific, 129(975):058007.

RMG (2017). Astronomy photographer of the year 2017.

Root-Bernstein, R. S. (1989). Discovering. Harvard University Press.

Salimpour, S., Bartlett, S., Fitzgerald, M. T., Cutts, K. R., James, C. R., Miller, S., Danaia, L., and et al (2018a). Robotic telescopes and student research in the school curriculum around the oecd countries. RTSRE Conference Proceedings, June 2017, San Diego California.

Salimpour, S., Bartlett, S., Fitzgerald, M. T., McKinnon, D. H., Cutts, K. R., James, C. R., Miller, S., Danaia, L., Hollow, R. P., Cabezon, S., et al. (2020). The gateway science: a review of astronomy in the oecd school curricula, including china and south africa. Research in Science Education, pages $1-22$.

Salimpour, S., Bartlett, S., Fitzgerald, M. T., McKinnon, D. H., Cutts, K. R., James, C. R., Miller, S., Danaia, L., Hollow, R. P., and et al (2018b). The gateway science: A review of astronomy in the school curriculum around the oecd countries. in prep.

Schoon, K. J. and Boone, W. J. (1998). Self-efficacy and alternative conceptions of science of preservice elementary teachers. Science Education, 82(5):553-568.

Settlage, J., Southerland, S. A., Smith, L. K., and Ceglie, R. (2009). Constructing a doubt-free teaching self: Self-efficacy, teacher identity, and 
science instruction within diverse settings. Journal of Research in Science Teaching: The Official Journal of the National Association for Research in Science Teaching, 46(1):102-125.

Shavelson, R. J. and Kurpius, A. (2012). Reflections on learning progressions. In Learning progressions in science, pages 13-26. Springer.

Sinatra, G. M., Broughton, S. H., and Lombardi, D. (2014). Emotions in science education. International handbook of emotions in education, pages 415-436.

Smith, C., Wiser, M., Anderson, C., Krajcik, J., and Coppola, B. (2004). Implications of research on children's learning for standards and assessment: Matter and the atomic molecular theory. Invited paper for the National Research Council committee on Test Design for K-12 Science Achievement. Washington, DC: National Research Council.

Smith, L. F., Arcand, K. K., Smith, J. K., Smith, R. K., and Bookbinder, J. (2015). Is that real? understanding astronomical images. Journal of Media and Communication Studies, 7(5):88-100.

Testa, I., Galano, S., Leccia, S., and Puddu, E. (2015). Development and validation of a learning progression for change of seasons, solar and lunar eclipses, and moon phases. Physical Review Special Topics-Physics Education Research, 11(2):020102.

Watts, M. (2001). Science and poetry: passion v. prescription in school science? International Journal of Science Education, 23(2):197-208.

Wickman, P.-O. (2006). Aesthetic experience in science education: Learning and meaning-making as situated talk and action. Routledge.

Zevin, D., Croft, S., Thrall, L., Fillingim, M., and Cook, L. (2015). Full steam ahead with the nasa opportunities in visualization, art, and science (novas) program. In Celebrating Science: Putting Education Best Practices to Work, volume 500, page 93.
Zimmerman, B. J. (2000). Self-efficacy: An essential motive to learn. Contemporary educational psychology, 25(1):82-91. 